\title{
Research of Education Evaluation Information Mining Technology Based on Gray Clustering Analysis and Fuzzy Evaluation Method
}

\author{
Yang Liu \\ College of Computer and Automatization, Tianjin Polytechnic University \\ Tianjin, 300160, China \\ E-mail: lynn_liu11@yahoo.com.cn \\ Junle $\mathrm{Yu}$ \\ College of Application Technology, Tianjin Polytechnic University \\ Tianjin, 300020, China \\ E-mail: junleye@126.com
}

Fund Project: Tianjin Education Sciences, "Eleventh Five-Year Plan" issues, issues No.: G016

\begin{abstract}
This paper has surveyed the education evaluation method and technology both at home and abroad, and studied on the question of education evaluation information's mining and synthesis processing. In view of the evaluation index system of high and secondary vocational education, on the basis of gray clustering analysis method this paper had established gray clustering model and applied fuzzy evaluation method to solve the question of education evaluation information synthesis processing. It provided a vastitude future of education evaluation information's mining and synthesis processing.
\end{abstract}

Keywords: Gray Clustering, Education Evaluation, Fuzzy Evaluation, Data Mining

\section{Introduction}

Education evaluation is that according to particular education value and education object, using operable science artifice, make value judgment on education action, processing and result by systemic collecting, analyzing and arranging information data. The result of judgment will provide a basis for continuous self-improvement and education decision. The issue of education evaluation information processing and data mining is an important issue of education evaluation research The solution of this issue will not only promote education quality improvement but also provide valuable reference information for increasing university teaching innovation and implementing the quality education. At the abroad the theory and application of education evaluation had a quickly development from this century, but the method and theory of evaluation information's integrated processing and data mining was behindhand in development relative to education evaluation investigation. So far, it is three representative education evaluation patterns including object direction evaluation pattern, decision direction evaluation pattern, pluralistic evaluation pattern in the development of abroad education evaluation. The education evaluation pattern investigation noted very little in the method and theory of information integrated processing and data mining. Each education evaluation had a definite value orientation, and these value orientations or value judgment were dominated by the study and application of information integrated processing and data mining theory and method.

Education is a complex system, so the integrated evaluation of complex system was needed many index to weighing. A part of internal study on education evaluation and evaluation index system was based on analytical hierarchy process, and found more science evaluation index system. When more science evaluation index system was found, we must choose a more precisely computation method. Accordingly, the researcher who at abroad and home had pay more attention to how choose a more precisely computation method in the education evaluation processing. In 1982, the famous researcher named Julong Deng in our country had brought up the gray system theory. The research object of gray system theory was uncertainty system what is unknown part of information's small sample or poor information. 
The gray clustering is the method that cluster several observation index or observation object into some definable classes by gray association matrix or gray number's whitely weight function. (Yannis Caloghirou. 1999)(Chen Z. 2001)(Qiu Jianrong, Zhang Xiaoping, Liu Hao, Wang Quanhai, Li Fan \& Zeng Hancai. 2002)(Gu Zhaojun, He Xiaohui, Si Zhensheng \& Fan Jingxin. 2007) A clustering can be considered as a set that observation was belonged same class. For the set what is constituted by all clustering object, we need not cluster by clustering index but also evaluate all evaluation object in a whole. For using data mining technology to point out the problem in the education evaluation and found the way to solve problem, this paper applies grey clustering analytic method as a basis and integration use fuzzy evaluation method(Sadaaki Miyamoto. 1990) to solve integration information processing in the education evaluation index system, thereby promote education evaluation's networking and informationization. At the same time according to high and secondary vocational education talented people training work level evaluation project, the paper use grey clustering method and fuzzy evaluation method to research and practice education evaluation in the evaluation project. The paper aspire after practicalness, pertinency and realistically in the content, materialize advanced and multiformity in the method, reach after science, justice and directional in the result. The research and solution of aforementioned problem will come about active effect and action for our country education evaluation technology.

\section{Education evaluation information integration processing and data mining}

The process of education evaluation data mining and information integration had three basic steps as follows:

\subsection{Construct education evaluation index system hierarchy model and confirm index weight}

After survey, education evaluation index system hierarchy's general model was confirmed by expert discussion again and again as figure 1 show:

We use AHP-GA method to confirm each index weight (also can be confirmed by experts researching). We assume that the weight vector what first index $B_{1}, B_{2}, \ldots, B_{n}$ relative to total object $\mathrm{A}$ is $b=\left(b_{1}, b_{2}, \ldots, b_{n}\right)$. The weight vector what layer C's weight relative to layer B's element $B_{n}$ is $c_{n}=\left(c_{1}, c_{2}, \ldots, c_{c n}\right)$. The $c n$ means that the number of layer C's element relative to element $B_{n}$. And for the same reason, the weight vector what layer D's weight relative to layer C's element $C_{m}$ is $d_{m}=\left(d_{1}, d_{2}, \ldots, d_{c m}\right)$.

\subsection{Construct grey clustering model}

\subsubsection{Construct evaluation value matrix}

It is assumed that the number of evaluation person was $p$, namely $t=1,2, \ldots p$. The number of evaluation object was $q$, namely $s=1,2, \ldots q$. From above index system, we assume that the number of first index was $n$, the number of second index was $m$ and the number of third index was $k_{m}$.

The evaluation person evaluates some evaluation object by third index's evaluation rank standard. We assume that the grade what the evaluation person $t$ evaluates on evaluation object $s$ by third index's evaluation rank standard was $d_{i j t}^{(s)}\left(i=1,2, \ldots, m ; j=k_{1}, \ldots, k_{i} ; t=1,2, \ldots, p ; s=1,2, \ldots, q\right)$, so the evaluation object $s$ 's evaluation value matrix $D^{(s)}$ was:

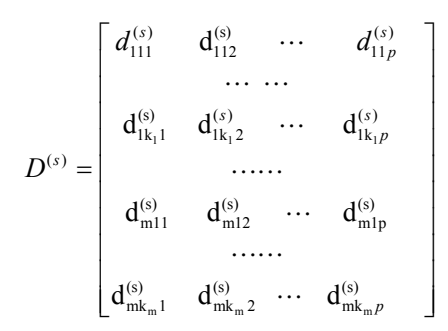

\subsubsection{Confirm evaluation grey class}

It should confirm the rank number of evaluation grey class, the grey number of grey class and grey class's whitely weight function by concretely education evaluation index system. It is assumed that the rank number of evaluation grey class was $g$, namely evaluation grey class was $e=1,2, \ldots, g$. The grey number is not a number, but it is a number set, or a space, is noted $\otimes$.

\subsubsection{Compute grey class's evaluation coefficient $\eta_{i j e}^{(s)}$.}

For the third index, by the whitely weight function $f_{e}\left(d_{i j k}^{(s)}\right)$ and the evaluation object $s$ 's value $d_{i j k}^{(s)}$, it computes grey evaluation coefficient $\eta_{i j e}^{(s)}$ which valuation object $s$ belongs to evaluation grey class $e$ as follows 


$$
\eta_{i j e}^{(s)}=\sum_{k=1}^{p} f_{e}\left(d_{i j k}^{(s)}\right)
$$

2.2.4 Compute grey evaluation weight $r_{i j e}^{(s)}$ and construct grey evaluation weight matrix.

The grey evaluation weight $r_{i j e}^{(s)}$ what evaluation person maintained grey $e$ on evaluation object $s$ by third evaluation indexes was:

$$
r_{i j e}^{(s)}=\eta_{i j e}^{(s)} / \sum_{e=1}^{g} \eta_{i j e}^{(s)}
$$

After colligating all grey class's evaluation object $s$ toward third evaluation indexes, the grey evaluation weight vector $r_{i j}^{(s)}$ is:

$r_{i j}^{(s)}=\left(r_{i j 1}^{(s)}, r_{i j 2}^{(s)}, \cdots, r_{i j g}^{(s)}\right)$

By colligating grey evaluation weight $r_{i j e}^{(s)}$ in the all of second index $C_{i}$ 's third index, it can be found that grey evaluation weight matrix $R_{i}^{(s)}$ of evaluation object $s$ 's second index $C_{i}$ toward each evaluation grey class is:

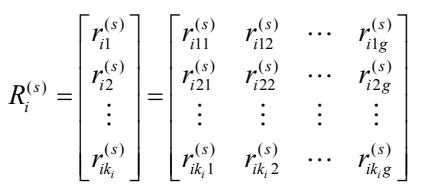

2.2.5 Compute grey integration evaluation vector $T T_{i}^{(s)}$ of second index $C_{i}$.

For the evaluation object $s$, according to $d_{i}=\left(d_{1}, d_{2}, \ldots, d_{c i}\right)$ that layer D's relatively weight vector corresponding layer C's element $C_{i}$ and grey evaluation weight matrix of second index $C_{i}$ toward each evaluation grey class, it can be evaluated integration, and then it found that grey integration evaluation vector $T T_{i}^{(s)}$ of evaluation object $s$ 's second index $C_{i}$ as follows:

$T T_{i}^{(s)}=d_{i} \cdot R_{i}^{(s)}=\left(t t_{i 1}^{(s)}, t t_{i 2}^{(s)}, \cdots, t t_{i g}^{(s)}\right)$

2.2.6 Compute grey integration evaluation vector $L T_{i}^{(s)}$ of first index $B_{n}$.

For the evaluation object $s$, by colligating grey integration evaluation vector $T T_{i}^{(s)}$ in the each second index $C_{i}$, it can be found that grey evaluation weight matrix $L_{i}^{(s)}$ of evaluation object $s$ 's first index $B_{n}$ toward each evaluation grey class is:

$L_{i}^{(s)}=\left[\begin{array}{c}T T_{1}^{(s)} \\ T T_{2}^{(s)} \\ \vdots \\ T T_{m}^{(s)}\end{array}\right]=\left[\begin{array}{cccc}t t_{11}^{(s)} & t t_{12}^{(s)} & \cdots & t t_{1 g}^{(s)} \\ t t_{21}^{(s)} & t t_{22}^{(s)} & \cdots & t t_{2 g}^{(s)} \\ \vdots & \vdots & \vdots & \vdots \\ t t_{m 1}^{(s)} & t t_{m 2}^{(s)} & \cdots & t t_{m g}^{(s)}\end{array}\right]$

According to $c_{n}=\left(c_{1}, c_{2}, \ldots, c_{c n}\right)$ that layer C's relatively weight vector corresponding layer B's element $B_{n}$ and grey evaluation weight matrix of first index $B_{n}$ toward each evaluation grey class, it can be evaluated integration, and then it found that grey integration evaluation vector $L T_{i}^{(s)}$ of evaluation object's first index $B_{n}$ as follows:

$$
L T_{i}^{(s)}=c_{n} \cdot L_{i}^{(s)}=\left(l t_{i 1}^{(s)}, l t_{i 2}^{(s)}, \cdots, l t_{i g}^{(s)}\right)
$$

\subsubsection{Compute clustering result.}

For the evaluation object $s$, by colligating grey integration evaluation vector $L T_{i}^{(s)}$ in the each first index $B_{i}(i=1,2, \ldots, n)$, it can be found that grey evaluation weight matrix $Z^{(s)}$ of evaluation object $s$ toward each evaluation grey class is: 
$Z^{(s)}=\left[\begin{array}{c}L T_{1}^{(s)} \\ L T_{2}^{(s)} \\ \vdots \\ L T_{m}^{(s)}\end{array}\right]=\left[\begin{array}{cccc}l t_{11}^{(s)} & l t_{12}^{(s)} & \cdots & l t_{1 g}^{(s)} \\ l t_{21}^{(s)} & l t_{22}^{(s)} & \cdots & l t_{2 g}^{(s)} \\ \vdots & \vdots & \vdots & \vdots \\ l t_{m 1}^{(s)} & l t_{m 2}^{(s)} & \cdots & l t_{m g}^{(s)}\end{array}\right]$

According to the weight vector $b=\left(b_{1}, b_{2}, \ldots, b_{n}\right)$ of first index $B_{i}(i=1,2, \ldots, n)$ and grey evaluation weight matrix $Z^{(s)}$ of evaluation object $s$, it can be clustered integration, and then it found that clustering result $X^{(s)}$ of evaluation object as follows:

$X^{(s)}=b \cdot Z^{(s)}=\left(x_{1}^{(s)}, x_{2}^{(s)}, \cdots, x_{g}^{(s)}\right)$

\subsection{Apply fuzzy evaluation to finding evaluation result}

It uses each grey class's threshold as rank value to compute the integration evaluation value of each evaluation object. For example, the grey class one's threshold is $d_{1}$, the grey class two's threshold is $d_{2}, \ldots$, the grey class g's threshold is $d_{g}$. So each grey class rank value vector is $F=\left(d_{1}, d_{2}, \cdots, d_{g}\right)$. The integration evaluation value $G^{(s)}$ of evaluation object $S$ is:

$G^{(s)}=X^{(s)} \cdot F^{T}$

It can be made an order by the value of $G^{(s)}$ after computing each evaluation object's integration evaluation value $G^{(s)}$.

\section{Demonstration test}

We use the evaluation process of high and secondary vocational education talented people training work level evaluation index system as example to explain the process of education evaluation information integration processing and data mining. According to the model of figure 1, firstly we have to confirm evaluation index's weight. Secondly, it evaluated on school A by five experts (data in table 1), then it found evaluation value matrix as follows:

$D=\left(\begin{array}{ccccc}8 & 7.5 & 8.5 & 8 & 7 \\ 7 & 6.5 & 7 & 6 & 7 \\ 6 & 6.5 & 7 & 6 & 6 \\ \vdots & \vdots & \vdots & \vdots & \vdots \\ 8 & 8.5 & 9 & 8 & 7.5 \\ 7.5 & 8 & 7 & 6 & 7\end{array}\right)$

According to grade standard of high and secondary vocational education talented people training work level evaluation project, it can be confirmed that the evaluation grey number is $e=5$, the whitely weight function is $f_{1}(x), f_{2}(x), f_{3}(x), f_{4}(x), f_{5}(x)$ as follows:

$$
\begin{array}{ll}
f_{1}(x)= \begin{cases}1 & x \in[9,+\infty] ; \\
\frac{1}{9} x & x \in[0,9]\end{cases} & f_{2}(x)= \begin{cases}1 & x \in[8,9] ; \\
\frac{1}{8} x & x \in[0,8] \cup[9,+\infty]\end{cases} \\
f_{3}(x)=\left\{\begin{array}{ll}
1 & x \in[7,8] ; \\
\frac{1}{7} x & x \in[0,7] \cup[8,+\infty]
\end{array} \quad f_{4}(x)= \begin{cases}1 & x \in[6,7] ; \\
\frac{1}{6} x & x \in[0,6] \cup[7,+\infty]\end{cases} \right. \\
f_{5}(x)= \begin{cases}1 & x \in[0,6] ; \\
\frac{1}{6} x & x \in[6,+\infty]\end{cases}
\end{array}
$$

It can be found that school A's all second index toward each evaluation grey class $R_{i}^{(s)}$ is (use first second index as example):

$$
R_{1}=\left[\begin{array}{l}
r_{11} \\
r_{12} \\
r_{13}
\end{array}\right]=\left[\begin{array}{ccccc}
0.587 & 0.205 & 0.102 & 0.100 & 0.006 \\
0.532 & 0.247 & 0.112 & 0.102 & 0.007 \\
0.514 & 0.234 & 0.152 & 0.100 & 0
\end{array}\right]
$$

Then, it can be found that grey evaluation weight matrix $L_{i}^{(s)}$ of first index's each evaluation grey class is (use first of first index as example):

$L_{1}=\left[\begin{array}{l}T T_{1} \\ T T_{2}\end{array}\right]=\left[\begin{array}{lllll}0.524 & 0.245 & 0.143 & 0.080 & 0.008 \\ 0.562 & 0.217 & 0.115 & 0.102 & 0.004\end{array}\right]$ 
Final, school A's clustering result is:

$X^{(A)}=(0.5521,0.2548,0.1821,0.007,0.004)$

Namely school A was belonged to first clustering (general comment above nine points), then it can be used fuzzy evaluation method to compute concretely general comment value as follows:

$G^{(A)}=9.3751$

According to above computing, it can be found that school A's evaluation result as table1 shows:

\section{Conclusion}

To sum up, in the practice application grey clustering method was relative agility. We had colligated fuzzy evaluation method and grey clustering method to clustering analyze and fuzzy evaluate on experts data; take integration analysis and advisement on evaluation index system's data. This method was more exactitude, more applied and more abundant what information shows compare with weighted averages method and other computation method. Foreign and Chinese had worked hard on the theory and application of grey clustering method. So we try to use this method to integrate process on education evaluation information in this paper, and the result was reasonable. The research result aspires after practicalness, pertinency and realistically in the content, materialize advanced and multiformity in the method, reach after science, justice and directional in the result, provide more strict and scientific method for the research of high and secondary vocational education evaluation information integration processing. At the same time, based on the research result building education evaluation database, evaluation model database and education evaluation information integration processing system on the Web was feasible and necessary. The research result was established stability basic for the development of our country's education evaluation technology.

\section{References}

Chen Z. (2001). An application of grey clustering method in the sporting clothing style evaluation. Journal of Systems Engineering and Electronics, v 12, n 2 (2001)19-22.

Gu Zhaojun, He Xiaohui, Si Zhensheng \& Fan Jingxin. (2007). Research on spam filtering based on grey clustering. Journal of Computational Information Systems, v 3, n 4 (2007)1713-1718.

Qiu Jianrong, Zhang Xiaoping, Liu Hao, Wang Quanhai, Li Fan \& Zeng Hancai. (2002). Grey clustering prediction for slagging potential of coal blends combustion. Combustion Science and Technology, v 174, n 3 (2002)51-70.

Sadaaki Miyamoto. (1990). Fuzzy sets in Information retrieval and Cluster Analysis (1 ${ }^{\text {st }}$ ed). Kluwer Academic Publishers.

Yannis Caloghirou. (1999). Mutivariate analysis for assessment of corporate performance. the case of Greece. Operational Tools in the Management of financial risks.

Table 1. School A's experts grading and General comment

\begin{tabular}{|c|r|r|r|r|r|}
\hline & E 1 & E & E & E & E \\
\hline $\begin{array}{c}\text { School orientation and } \\
\text { develop programming }\end{array}$ & 8 & 7.5 & 8.5 & 8 & 7 \\
\hline Education thinking concept & 7 & 6.5 & 7 & 6 & 7 \\
\hline $\begin{array}{c}\text { Teaching center position } \\
\text { Study and teaching }\end{array}$ & 6 & 6.5 & 7 & 6 & 6 \\
\hline $\begin{array}{c}\text { proportion between student } \\
\text { and teacher }\end{array}$ & 8 & 8 & 8.5 & 8 & 7.5 \\
\hline $\begin{array}{c}\text { Non-plurality teacher } \\
\text { proportion }\end{array}$ & 9 & 8.5 & 9 & 8 & 8.5 \\
\hline $\begin{array}{c}\text { plurality teacher's quantity } \\
\text { and structure }\end{array}$ & 8 & 8.5 & 9 & 8 & 7.5 \\
\hline \begin{tabular}{c} 
Quality \\
\hline
\end{tabular} & 8 & 8.5 & 9 & 7.5 & 8 \\
\hline
\end{tabular}




\begin{tabular}{|c|c|c|c|c|c|}
\hline $\begin{array}{l}\text { Construction and } \\
\text { development }\end{array}$ & 9 & 8.5 & 9 & 8.5 & 8 \\
\hline $\begin{array}{l}\text { Teaching administration } \\
\text { house }\end{array}$ & 7 & 8 & 8.5 & 9 & 8 \\
\hline $\begin{array}{l}\text { Teaching instrument } \\
\text { equipment }\end{array}$ & 8 & 9 & 8.5 & 8 & 7.5 \\
\hline Library and campus net & 7 & 6 & 6.5 & 8 & 7.5 \\
\hline $\begin{array}{l}\text { Athletic sports } \\
\text { establishment }\end{array}$ & 9 & 8.5 & 8 & 7.5 & 8.5 \\
\hline Practice condition in school & 8 & 8.5 & 8.5 & 9 & 7.5 \\
\hline Practice base out of school & 7 & 8 & 8.5 & 7.5 & 7.5 \\
\hline Profession skill appraisal & 6 & 8 & 7 & 6.5 & 7 \\
\hline Outlay pledge complexion & 8.5 & 9 & 9.5 & 8 & 8.5 \\
\hline Teaching outlay proportion & 6.5 & 7 & 7.5 & 6 & 7 \\
\hline Major setting & 7 & 8.5 & 8 & 7.5 & 9 \\
\hline Teaching plan & 8 & 8.5 & 9 & 7.5 & 8.5 \\
\hline Major teaching innovation & 9.5 & 9 & 8.5 & 9 & 9.5 \\
\hline $\begin{array}{l}\text { Teaching content and } \\
\text { course innovation }\end{array}$ & 8.5 & 9 & 8.5 & 8 & 9 \\
\hline $\begin{array}{l}\text { Teaching material } \\
\text { construction }\end{array}$ & 7 & 8 & 8.5 & 7 & 9 \\
\hline Teaching method & 7.5 & 8.5 & 8 & 7.5 & 8 \\
\hline Practice training system & 8 & 8.5 & 9 & 7.5 & 8 \\
\hline Profession ability checking & 8.5 & 8 & 8.5 & 9 & 8 \\
\hline $\begin{array}{l}\text { Work state and impact on } \\
\text { all around education }\end{array}$ & 7.5 & 8 & 8.5 & 9 & 8 \\
\hline $\begin{array}{l}\text { Teaching manage and } \\
\text { student manage }\end{array}$ & 8 & 9 & 8 & 9 & 9.5 \\
\hline $\begin{array}{c}\text { Teaching bylaw's } \\
\text { construction and perform }\end{array}$ & 8.5 & 8 & 9 & 8.5 & 8 \\
\hline $\begin{array}{l}\text { Quality standard of major } \\
\text { teaching tache }\end{array}$ & 7 & 7 & 7 & 8 & 7.5 \\
\hline $\begin{array}{l}\text { Teaching quality monitor } \\
\text { and student quality research }\end{array}$ & 7.5 & 8 & 8.5 & 7 & 7.5 \\
\hline Profession ability & 6 & 8 & 6.5 & 6 & 7 \\
\hline Necessary knowledge & 8.5 & 8.5 & 8.5 & 9 & 7 \\
\hline Basic diathesis & 7 & 7.5 & 6 & 8 & 7 \\
\hline $\begin{array}{l}\text { Register rate and } \\
\text { employment rate }\end{array}$ & 8 & 8.5 & 9 & 8 & 7.5 \\
\hline Graduate evaluation & 7.5 & 8 & 7 & 6 & 7 \\
\hline General comment & \multicolumn{5}{|c|}{9.3751} \\
\hline
\end{tabular}




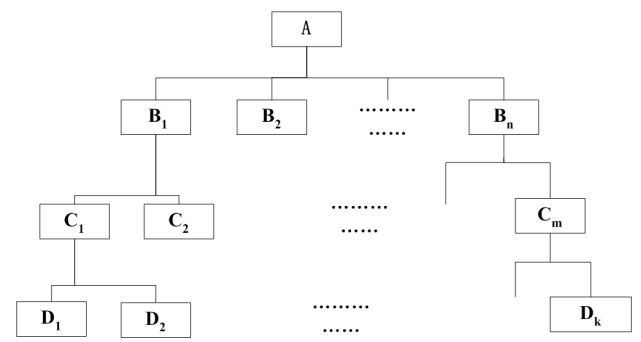

Figure 1. Education evaluation system hierarchy diagram 